\title{
Infection prevention knowledge, practice, and its associated factors among healthcare providers in primary healthcare unit of Wogdie District, Northeast Ethiopia, 2019: a cross-sectional study
}

\author{
Jemal Assefa', Gedefaw Diress ${ }^{2^{*}}$ (D) and Seteamlak Adane ${ }^{2}$
}

\begin{abstract}
Background: Adequate knowledge and safe practice of infection prevention among healthcare providers are vital to prevent nosocomial infections. Thus, this study aimed to assess the level of knowledge and practices of healthcare providers towards infection prevention and its associated factors in the health facilities of Wogdie District, Northern Ethiopia.

Methods: Institution based cross-sectional study was conducted among 171 healthcare providers who were selected by a simple random sampling technique. Data were collected using interviewer-administered questionnaire. Multivariable logistic regression was performed to identify factors associated with knowledge and practice of infection prevention.

Result: About 70.8 and $55.0 \%$ of healthcare providers had adequate knowledge and safe practice of infection prevention respectively. Having infection prevention guideline $(A O R=3.65,95 \% C l ; 1.26,10.54)$, taking infection prevention training $(A O R=2.2,95 \% C l ; 1.01,4.75)$, having five years or more work experience $(A O R=1.52$ : $95 \% \mathrm{Cl} ; 1.13,4.51)$, and working in maternity unit (AOR $=1.67: 95 \% \mathrm{Cl} ; 1.38-5.23$ ) were positively associated with adequate knowledge of infection prevention. The odds of safe practice were higher in participants who received infection prevention training (AOR: $2.4 ; 95 \% \mathrm{Cl} ; 1.01,4.75)$ but lower among healthcare providers who are working in the facility which has no continuous water supply $(\mathrm{AOR}=0.48: 95 \% \mathrm{Cl} ; 0.21,0.83$ ).

Conclusion: A significant proportion of healthcare providers had inadequate knowledge and unsafe practice of infection prevention. To improve healthcare worker's knowledge of infection prevention, adequate preservice as well as on job training should be given.
\end{abstract}

Keywords: Knowledge, Practice, Infection prevention, Wogdie

\footnotetext{
* Correspondence: gedefawdiress@gmail.com

${ }^{2}$ Department of Public Health, College of Health Science, Woldia University, Woldia, Ethiopia

Full list of author information is available at the end of the article
}

(c) The Author(s). 2020 Open Access This article is licensed under a Creative Commons Attribution 4.0 International License, which permits use, sharing, adaptation, distribution and reproduction in any medium or format, as long as you give appropriate credit to the original author(s) and the source, provide a link to the Creative Commons licence, and indicate if changes were made. The images or other third party material in this article are included in the article's Creative Commons licence, unless indicated otherwise in a credit line to the material. If material is not included in the article's Creative Commons licence and your intended use is not permitted by statutory regulation or exceeds the permitted use, you will need to obtain permission directly from the copyright holder. To view a copy of this licence, visit http://creativecommons.org/licenses/by/4.0/. The Creative Commons Public Domain Dedication waiver (http://creativecommons.org/publicdomain/zero/1.0/) applies to the data made available in this article, unless otherwise stated in a credit line to the data. 


\section{Background}

Healthcare-associated infection is defined as infections acquired in the healthcare facilities during the clinical, diagnostic and therapeutic procedure that was not present at the time of the client's admission [1]. It is a main problem encountered in healthcare delivery services worldwide and constitutes one of the most important causes of morbidity and mortality [1-3]. A systematic review of the literature reported that the pooled prevalence of healthcare associated infection was $7.6 \%$ in high-income countries and $10.1 \%$ in low and middleincome countries [4].

In Africa including Ethiopia, the prevalence of hospitalacquired infection was significantly high (12-35\%) [5-8]. However, awareness of the problem remains extremely limited because of other health priorities take precedence over infection prevention and patient safety considerations [4]. Most of the healthcare associated infections are caused by the transmission of pathogens from one patient to another, especially by healthcare workers who failed to practice infection prevention measures consistently [9-12].

In Africa, many studies have shown that significant proportion of healthcare providers had inadequate knowledge on infection prevention. Only $58 \%$ of health care workers in Ghana [13] and $70-80 \%$ in Nigeria [14, 15] had adequate knowledge about infection prevention. Similarly, past evidence in Ethiopia showed that merely $54-60 \%$ of healthcare providers had adequate knowledge about infection prevention [16-18] and only $32-55 \%$ of healthcare providers demonstrated a safe practice on infection prevention $[15,17,19]$.

Studies have shown that different factors such as availability of infection prevention guidelines, training on infection prevention and availability of personal protection equipment can promote safe infection prevention practices at the hospital level $[16-18,20]$. However, the factors associated with knowledge and practice of infection prevention in the primary health care unite of Ethiopia have not previously been explored.

The Federal Ministry of Health (FMoH) of Ethiopia started initiatives to protect patients and health workers from healthcare associated infection by setting infection prevention standards and guidelines. Adequate knowledge of infection prevention is crucial to implement these infection prevention standards and to improve infection prevention practice. However, very little has been published on the level of knowledge and practices towards infection prevention among health workers in Ethiopia. Besides, the majority of previous studies [17, 21-23] in Ethiopia have done at the hospital level which differs from the primary health care unit in regarding to staff profile, infrastructure, training and financial support. Therefore, this study aimed to assess the knowledge and practices towards infection prevention and its associated factors among primary healthcare providers in Wogdie district, Northern Ethiopia.

\section{Methods \\ Study design, setting and population}

Institutional-based cross-sectional study design was conducted from February to May in Wogdie district which is located in the Northern part of Ethiopia. It is $581 \mathrm{Km}$ away from Addis Ababa (the capital city of the country) and $640 \mathrm{Km}$ from Bihar Dar (regional capital city). According to Wogdie woreda health office 2019 annual plan, the district had a total population of 155, 960 and it has one governmental primary Hospital and five health centers. All healthcare workers (Laboratory, Nurse, Health officer, and Midwifery) working in all three departments of healthcare facilities (Out-patient, In-patient and Emergency department) and providing care and have direct involvement in patient care were eligible to be included in the study. Healthcare providers who were on annual leave for longer than 2 weeks, maternity leave and who were critically ill during the study period were excluded.

\section{Sample size determination \& sampling technique}

The sample size was determined by using single population proportion formula by considering the proportion of practices on infection prevention method $87.5 \%$, from the study conducted in Dessie Referral Hospital [24] using the assumptions: 95\% confidence interval, 5\% margin of error. The calculated sample size was 162 but after adding a $5 \%$ non-response rate, the final sample size became 171. A simple random sampling technique (table of random number) was used to select the representative subjects from all healthcare providers list in the Woreda Health Office.

\section{Variables}

The outcome of interest was knowledge (adequate/inadequate) and practice (safe/unsafe) towards infection prevention. Independent variables include socio-demographic characteristics, water supply, presence of infection prevention committee, presence of infection prevention guidelines in a health facility and training on infection prevention. Knowledge of infection prevention was computed from 11 questions. The mean value was used to classify HCWs infection prevention knowledge as having adequate knowledge if the score was equal or above the mean. Respondents who scored less than the mean value of correct answers were classified as having inadequate knowledge on the infection prevention. Infection prevention practices of healthcare provides were assessed for main components of infection prevention measures like hand hygiene practices, utilization of personal protective equipment (PPE), and post-exposure prophylaxes (PEP), 
healthcare waste management practices, and instrument disinfection practice. Respondents were asked to indicate the frequency of use (practice) for these 7 infection prevention measures. Practice assessment questions had either three or two possible alternative responses ("Always" or "Yes", "Sometimes" and "Never" or "No"). One point was given for each acceptable or correct practice and zero point for all other responses. Practice scores were summed up to give a total practice score for each healthcare worker. Therefore, the total score of practice questions ranging from zero (all prevention measures not practiced safely) to seven (all infection prevention measures practiced safely) were classified into two categories of response: safe practice (equal or above the mean) and unsafe practice (below the mean) $[25,26]$.

\section{Data collection techniques}

Two trained BSc Nurses collected the data through faceface interview using a structured and pre-tested questionnaire which was prepared in the local language (Amharic). The tool was developed after reviewing related kinds of literature [2, 17, 18, 24, 27]. Data collectors were trained and supervised during the data collection period.

\section{Data quality control}

To assure the data quality, data collection instruments were pre-tested on $5 \%$ of the sample on two health centers of Borena woreda. For each component, a reliability test was done. The reliability coefficient for practice and knowledge items had a Cronbach's Alpha value of 0.832 and 0.753 respectively. The data were examined for completeness and consistency during data collection on a daily base by the supervisor.

\section{Data analysis}

Data were entered using Epi-data version 3.1 and analyzed by SPSS version 20. Before analysis, data were cleaned and checked for outliers and missing's. Logistic regression was done and variables with a $P$-value of less than 0.2 at bivariable logistic regression model were entered into the multivariable logistic regression model. In all cases, $p$-values of less than 0.05 were considered as statistically significant.

\section{Result}

\section{Socio-demographic characteristics}

In this study, a total of 171 study participants were included and the mean age of the study participants was 27.98 with $\mathrm{SD} \pm 3.56$ years. Of the total participants, 119 $(69.6 \%)$ of them were males and the majority 110 (64.3\%) were married. About 83(48.5\%) study participants were Nurses regardless of their educational level. In terms of educational status, 102(59.6\%) study participants were diploma and nearly one-third of respondents were currently working at the outpatient clinics (Table 1).

More than two-thirds of health facilities had infection prevention committee and around $73 \%$ of health facilities had infection prevention guidelines. About 33(19.3\%) study participants didn't take any training on infection prevention and universal precaution (Table 2).

\section{Knowledge of health care providers on infection prevention}

In this study, $70.8 \%$ of participants had adequate knowledge about infection prevention. Sixteen $(9.4 \%)$ were believed that gloves cannot provide complete protection against acquiring infection. One hundred sixty-three (95.3\%) of the study participants responded that washing hands with soap or an alcohol-based antiseptic decreases the risk of transmission of hospital acquired pathogens (Table 3).

\section{Practice of health care providers on infection prevention} In this study, $55 \%$ of healthcare providers had safe infection prevention practice. From all participants, 68.4\% wash their hands before patient care and $77.2 \%$ used soap to wash their hands. Around $50.3 \%$ of healthcare providers have used all personal protective equipment's and $90.6 \%$ participant changes chlorine solution every 24. h (Table 4).

\section{Factors associated with knowledge of infection prevention}

In this study, all variables with a $P$-value of less than 0.2 at bivariate logistic regression model were included in the multivariable analysis. Thus age, sex, educational status, profession, work experience, presence of infection prevention guideline, getting of infection prevention training, availability of continuous water supply, type of health center and currently working unit were evaluated as possible factors associated with knowledge of infection prevention. But, we removed two variables; type of health center and member of infection prevention committee to avoid multicollinearity (detected through chi-square test). In multivariable analysis presence of IP guidelines, IP training, work experience and currently working unit were significantly associated with knowledge of infection prevention $(P<$ 0.05). The odds of having adequate knowledge of infection prevention among health care providers who have IP guidelines in their health institutions were 3.7 times higher (AOR: 3.65, 95\% CI;1.26, 10.54) than those who have not IP guideline. The odds of having adequate knowledge towards infection prevention were higher in health worker who has trained about infection prevention $(\mathrm{AOR}=2.19$ : 95\% CI; 1.01, 4.75) than those who were not trained. Similarly, participants who had more than 5 years' work 
Table 1 Socio-demographic characteristic of health care providers in five health facilities of Wogdie district, South Wollo zone, Amhara region, Ethiopia, 2019

\begin{tabular}{|c|c|c|c|}
\hline Variables & Category & Frequency & Percentage (\%) \\
\hline \multirow[t]{3}{*}{ Age } & $18-27$ & 84 & 49.1 \\
\hline & $28-37$ & 82 & 48.0 \\
\hline & $38-47$ & 5 & 2.9 \\
\hline \multirow[t]{2}{*}{ Sex } & Male & 119 & 69.6 \\
\hline & Female & 52 & 30.4 \\
\hline \multirow[t]{2}{*}{ Marital status } & Married & 110 & 64.3 \\
\hline & Single & 61 & 35.7 \\
\hline \multirow[t]{5}{*}{ Profession } & Nurse & 68 & 39.8 \\
\hline & Midwifery & 33 & 19.3 \\
\hline & Health Officer & 26 & 15.1 \\
\hline & Laboratory technologist/technician & 29 & 17.0 \\
\hline & Pharmacist/pharmacy-technician & 15 & 8.8 \\
\hline \multirow[t]{2}{*}{ Educational status } & Degree and above & 69 & 40.3 \\
\hline & Diploma & 102 & 59.7 \\
\hline \multirow[t]{2}{*}{ Work experience in health facility } & Less than 5 years & 114 & 66.7 \\
\hline & $>=5$ years & 57 & 33.3 \\
\hline \multirow[t]{7}{*}{ Currently working unit } & Outpatient department & 51 & 29.8 \\
\hline & Emergency and Triage & 22 & 12.9 \\
\hline & Maternity unit & 33 & 19.3 \\
\hline & Inpatient clinic & 13 & 7.5 \\
\hline & Laboratory & 29 & 17.0 \\
\hline & Pharmacy & 15 & 8.8 \\
\hline & Under-five clinic & 8 & 4.7 \\
\hline
\end{tabular}

experience had higher odds of having adequate infection prevention knowledge (AOR $=1.52$ : 95\% CI; 1.13-4.51). Healthcare providers who were currently working in maternity and laboratory unit had higher odds of having adequate knowledge about IP $((\mathrm{AOR}=1.67: 95 \% \mathrm{CI}$; $1.38-$ $5.23), \quad(\mathrm{AOR}=2.56: 95 \% \mathrm{CI} ; \quad 1.26-4.13)) \quad$ respectively (Table 5).

\section{Factors associated with infection prevention practice}

In this study, age, sex, educational status, profession, work experience, presence of infection prevention guideline, getting of infection prevention training, availability of continuous water supply, type of health center and currently working unit were evaluated as possible factors associated with safe infection prevention practices. But,

Table 2 Characteristic of health care providers in Wogdie district, South Wollo Zone, Amhara region, Ethiopia, 2019

\begin{tabular}{|c|c|c|c|}
\hline Characteristics & Category & Frequency & Percentage (\%) \\
\hline \multirow[t]{2}{*}{ Type of health facility } & Rural Health center & 98 & 57.3 \\
\hline & Urban health center & 73 & 42.7 \\
\hline \multirow[t]{2}{*}{ Members of infection prevention committee } & Yes & 119 & 69.5 \\
\hline & No & 52 & 30.5 \\
\hline \multirow[t]{2}{*}{ Access infection prevention guideline } & Yes & 124 & 72.5 \\
\hline & No & 47 & 27.5 \\
\hline \multirow[t]{2}{*}{ Infection prevention training } & Yes & 58 & 33.9 \\
\hline & No & 113 & 66.1 \\
\hline \multirow[t]{2}{*}{ Availability of continuous water supply } & Yes & 88 & 51.5 \\
\hline & No & 83 & 48.5 \\
\hline
\end{tabular}


Table 3 Knowledge questions for health care providers in health facilities of Wogdie district, South Wollo zone, Amhara region, Ethiopia ( $n=171), 2019$

\begin{tabular}{|c|c|c|c|}
\hline Knowledge Variables & Category & Frequency & Percentage (\%) \\
\hline \multirow[t]{2}{*}{ Have you heard about infection prevention principle? } & Yes & 171 & 100 \\
\hline & No & 0 & 0 \\
\hline \multirow{2}{*}{$\begin{array}{l}\text { Do you think that gloves cannot provide complete protection } \\
\text { against acquiring/transmitting infection? }\end{array}$} & Yes & 155 & 90.6 \\
\hline & No & 16 & 9.4 \\
\hline \multirow{2}{*}{$\begin{array}{l}\text { Do you think that healthcare-associated pathogens can be } \\
\text { found on normal and intact patient skin? }\end{array}$} & Yes & 163 & 95.3 \\
\hline & No & 18 & 4.7 \\
\hline \multirow{2}{*}{$\begin{array}{l}\text { Do you think that washing your hands with soap or alcohol-based } \\
\text { antiseptic decreases the risk of transmission of hospital acquired infection? }\end{array}$} & Yes & 163 & 95.3 \\
\hline & No & 8 & 4.7 \\
\hline \multirow{2}{*}{$\begin{array}{l}\text { Do you think that use of an alcohol-based antiseptic for hand } \\
\text { hygiene is as effective as soap and water if hands are not visibly dirty? }\end{array}$} & Yes & 168 & 98.2 \\
\hline & No & 3 & 1.8 \\
\hline \multirow{2}{*}{$\begin{array}{l}\text { Do you think that gloves reduce the contamination of the hand } \\
\text { but do not prevent it completely? }\end{array}$} & Yes & 137 & 80.1 \\
\hline & No & 34 & 19.9 \\
\hline \multirow{2}{*}{$\begin{array}{l}\text { Do you think that no need to wash hands before doing procedures } \\
\text { that do not involve bodily fluids? }\end{array}$} & Yes & 33 & 19.3 \\
\hline & No & 138 & 80.7 \\
\hline \multirow{2}{*}{$\begin{array}{l}\text { Do you think that no need to wear the same pair of gloves for } \\
\text { multiple patients as long as there is no visible contamination? }\end{array}$} & Yes & 130 & 76.0 \\
\hline & No & 41 & 24 \\
\hline \multirow{2}{*}{$\begin{array}{l}\text { Do you think TB is carried in airborne particles that are generated } \\
\text { from patients with active pulmonary TB? }\end{array}$} & Yes & 169 & 98.8 \\
\hline & No & 2 & 1.2 \\
\hline \multirow{2}{*}{$\begin{array}{l}\text { Do you know to what level safety boxes should be filled before closing } \\
\text { and sealing? }\end{array}$} & Full & 16 & 9.4 \\
\hline & $3 / 4$ full & 155 & 90.6 \\
\hline \multirow{2}{*}{$\begin{array}{l}\text { Do you know specific waste disposal buckets according to the level } \\
\text { of their contamination? }\end{array}$} & Yes & 167 & 97.7 \\
\hline & No & 4 & 2.3 \\
\hline
\end{tabular}

getting infection prevention training and the availability of continuous water supply in the health facility were significantly associated $(P<0.05)$ with safe infection prevention practices in the multivariable analysis. Healthcare providers who have trained on infection prevention were 2.2 times (AOR: 2.19, 95\% CI; 1.01-4.75) more likely to have good practice than those who were not trained. The odds of safe infection prevention practices were 52\% lower among healthcare providers who work in health facility which have not continuous water supply $(\mathrm{AOR}=0.48: 95 \% \mathrm{CI} ; 0.214-0.832))$ than their counterparts (Table 6).

\section{Discussion}

Adequate knowledge about infection prevention is vital in reducing healthcare-associated infection. The finding in this study suggested that approximately one-third of healthcare providers working in primary healthcare unit demonstrated inadequate knowledge about infection prevention. This finding is supported by previous studies [14, 16, 28] done in different parts of Africa. But it was low when compared with studies done in Ethiopia [17, 23]. This discrepancy may be due to differences in the study settings. The majority of previous studies were done at teaching and referral hospitals but this study was limited to the primary healthcare units (health centers). In teaching and referral hospitals healthcare providers might get the opportunities for various infection prevention training which could increase knowledge level about infection prevention [14, 29].

Even though $\mathrm{FMoH}$ of Ethiopia is scaling-up its activities related with infection prevention, the current study showed that only $55 \%$ of healthcare providers had safe infection prevention practices. This finding was in line with a study done in Bahir-Dar [23] but lower when compared with studies done in other parts of Ethiopia $[24,30]$. The discrepancy might be due to a difference in the study setting and composition of healthcare providers [24]. In Ethiopia, the composition of health worker staffs were different among hospitals and primary healthcare unit. Majority of health workers in hospitals were experienced and specialized which might improve their practice towards infection prevention. This finding implies that improving safe infection prevention practices are vital in primary healthcare units of Ethiopia where a high proportion of patients developed healthcare associated infection [31]. 
Table 4 Infection prevention practice questions for health care providers in health facilities of Wogdie district, South Wollo zone, Amhara region, Ethiopia $(n=171)$, June 2019

\begin{tabular}{|c|c|c|c|}
\hline Variables & Category & Frequency(N) & $\begin{array}{l}\text { Percentage } \\
(\%)\end{array}$ \\
\hline \multirow{3}{*}{$\begin{array}{l}\text { How often you wash your hands with proper detergent after } \\
\text { contact with patient? }\end{array}$} & Always & 68 & 39.8 \\
\hline & Sometimes & 87 & 50.9 \\
\hline & Never & 16 & 9.3 \\
\hline \multirow[t]{2}{*}{ Do you use antiseptic hand rub to clean hands? } & Yes & 160 & 93.6 \\
\hline & No & 11 & 6.4 \\
\hline \multirow{2}{*}{$\begin{array}{l}\text { How often do you use all personal protective equipment's } \\
\text { as per standard to prevent infection? }\end{array}$} & Always & 86 & 50.3 \\
\hline & Some times & 85 & 49.7 \\
\hline \multirow{2}{*}{$\begin{array}{l}\text { When do you change chlorine solutions that used for instrumental } \\
\text { processing? }\end{array}$} & Every $24 \mathrm{~h}$ & 155 & 90.6 \\
\hline & After 2 days & 16 & 9.4 \\
\hline \multirow{2}{*}{$\begin{array}{l}\text { How often do you use glove when you perform procedures that need } \\
\text { wearing glove? }\end{array}$} & Always & 142 & 83.0 \\
\hline & Some times & 29 & 17.0 \\
\hline \multirow{2}{*}{$\begin{array}{l}\text { Have you ever exposed to blood or other body fluids of patients } \\
\text { through contact or unprotected skin? }\end{array}$} & Yes & 122 & 71.3 \\
\hline & No & 49 & 28.7 \\
\hline \multirow{7}{*}{$\begin{array}{l}\text { What measure did you take if you are exposed to blood or fluids, } \\
\text { needle stick injury? }\end{array}$} & Only taking Post exposure prophylaxis & 19 & 11.1 \\
\hline & Only clean by alcohol & 68 & 39.8 \\
\hline & Only washing with water & 2 & 1.2 \\
\hline & $\begin{array}{l}\text { Taking Post exposure prophylaxis and clean by } \\
\text { alcohol }\end{array}$ & 32 & 18.7 \\
\hline & $\begin{array}{l}\text { Taking post exposure prophylaxis and washing } \\
\text { with water }\end{array}$ & 7 & 4.1 \\
\hline & Clean by alcohol and washing with water & 14 & 8.2 \\
\hline & All action taken & 29 & 17.0 \\
\hline \multirow{2}{*}{$\begin{array}{l}\text { Did you practice high-level disinfection where sterilization is } \\
\text { not applicable? }\end{array}$} & Yes & 124 & 72.5 \\
\hline & No & 47 & 27.5 \\
\hline \multirow[t]{2}{*}{ What is your facility sterilization technique? } & Boiling & 19 & 11.1 \\
\hline & steam sterilization & 152 & 88.9 \\
\hline
\end{tabular}

Remarkably, in the current study, about $90 \%$ of health care providers believed that gloves can't provide complete protection against acquiring infection. This finding is higher than previous studies done in Ethiopia [17, 18] and Eritrea [32]. As similar to previous studies done in Ethiopia [17, 27], in this study, only one-third of healthcare providers had hand hygiene practice after patient care and $68.4 \%$ of healthcare workers wash their hands before patient care.

This study revealed that healthcare providers who had more than five years of work experience were 1.5 times more likely to have adequate knowledge than their counterparts. This is in line with findings from Ethiopia [17, 25]. This might be due to the fact that as the number of years of practice increases, healthcare providers are exposed to infection prevention information and became more experienced through working with senior staff.
According to WHO recommendation, all primary healthcare facilities should develop their own standard operating procedures based on national infection prevention and control guidelines [33, 34]. Developing and implementation of infection prevention guidelines is one of the core components of infection prevention and control programs at all healthcare facilities [33, 34]. In this study, similar to previous studies [18, 22], the presence of infection prevention guidelines in health institutions also increases the odds of having adequate knowledge about infection prevention. This might be attributed to the fact that healthcare workers who have infection prevention guidelines were more likely to get updated information, which improves their knowledge of infection prevention.

Healthcare providers who are currently working in maternity and laboratory unit had higher odds of having adequate knowledge about IP. This might be due to the availability of infection prevention standard operating 
Table 5 Bivariate and multivariate logistic regression of factors associated with knowledge of health care providers towards infection prevention of Wogdie district, south Wollo zone Amhara region, Ethiopia, 2019

\begin{tabular}{|c|c|c|c|c|c|}
\hline \multirow[t]{2}{*}{ Characteristics } & & \multicolumn{2}{|c|}{ Knowledge status } & \multirow[t]{2}{*}{ COR $(95 \% \mathrm{Cl})$} & \multirow[t]{2}{*}{ AOR $(95 \% C l)$} \\
\hline & & Adequate & Inadequate & & \\
\hline \multirow[t]{2}{*}{ Sex } & Male & $80(67.2)$ & $39(32.8)$ & $0.55(0.25-1.18)$ & $1.03(0.34-3.09)$ \\
\hline & Female & $41(78.8)$ & $11(21.2)$ & 1 & 1 \\
\hline \multirow[t]{2}{*}{ Educational status } & Diploma & $65(63.7)$ & $37(37.3)$ & 1 & 1 \\
\hline & Degree & $53(80.3)$ & 13(19.7) & $2.47(1.17-5.20)$ & $1.05(0.32-3.44)$ \\
\hline \multirow[t]{2}{*}{ Work experience } & $<5$ Years & $75(65.7)$ & $39(34.3)$ & 1 & 1 \\
\hline & $>=5$ years & $46(80.7)$ & 11(19.3) & $0.46(0.21-0.98)$ & $1.52(1.13-4.51) *$ \\
\hline \multirow[t]{2}{*}{ IP Guideline } & Yes & 100(80.6) & 24(19.4) & $5.16(2.49-10.68)$ & $3.65(1.26-10.54) *$ \\
\hline & No & $21(44.7)$ & $26(55.3)$ & 1 & 1 \\
\hline \multirow[t]{2}{*}{ IP Training } & Yes & $32(42.1)$ & $26(24.8)$ & $17.64(6.87-45.33)$ & $2.19(1.01-4.75)^{*}$ \\
\hline & No & $44(57.9)$ & $79(75.2)$ & 1 & 1 \\
\hline \multirow[t]{7}{*}{ Currently working unit } & Outpatient department & $30(32.2)$ & 21(26.9) & 1 & \\
\hline & Emergency and Triage & $6(6.5)$ & $16(20.5)$ & $1.25(0.53-2.04)$ & $0.25(0.13-1.54)$ \\
\hline & Maternity unit & $23(24.7)$ & $10(12.8)$ & $1.31(1.08-3.38)$ & $1.67(1.38-5.23)^{*}$ \\
\hline & Inpatient clinic & $8(8.6)$ & $5(6.4)$ & $0.78(0.25-2.81)$ & $1.38(0.48-2.51)$ \\
\hline & Laboratory & $15(16.1)$ & 14(17.9) & $1.46(1.13-3.43)$ & $2.56(1.26-4.13)^{*}$ \\
\hline & Pharmacy & $6(6.5)$ & $9(11.5)$ & $0.84(0.39-3.03)$ & $0.54(0.17-1.57)$ \\
\hline & Under-five clinic & $5(5.4)$ & $3(3.8)$ & $0.91(0.32-1.84)$ & $0.87(0.57-3.47)$ \\
\hline
\end{tabular}

IP infection prevention, COR crude odds ratio, AOR adjusted odds ratio; ${ }^{*}=$ significantly associated at $P<0.05$

Table 6 Bivariable and multivariable logistic regression of factors associated with infection prevention practice of health care providers in Wogdie district, south Wollo zone, Amhara region, Ethiopia 2019

\begin{tabular}{|c|c|c|c|c|c|}
\hline \multirow[t]{2}{*}{ Characteristics } & & \multicolumn{2}{|c|}{ Infection prevention practice status } & \multirow[t]{2}{*}{ COR 95\% Cl } & \multirow[t]{2}{*}{ AOR 95\% Cl } \\
\hline & & Safe & Unsafe & & \\
\hline \multirow[t]{2}{*}{ Sex } & Male & $80(67.2)$ & 39(32.8) & $0.55(0.26-1.19)$ & $1.21(0.52-2.80)$ \\
\hline & Female & $41(78.8)$ & $11(21.2)$ & 1 & 1 \\
\hline \multirow[t]{2}{*}{ Educational status } & Degree & $53(80.3)$ & 13(19.7) & $2.47(1.17-5.20)$ & $0.78(0.32-1.91)$ \\
\hline & Diploma & $65(63.7)$ & $37(37.3)$ & 1 & 1 \\
\hline \multirow[t]{2}{*}{ Work experience } & $<5$ Years & $75(65.7)$ & $39(34.3)$ & $0.46(0.21-0.99)$ & 0.89(0.42-1.913) \\
\hline & $>=5$ years & $46(80.7)$ & $11(19.3)$ & 1 & 1 \\
\hline \multirow[t]{2}{*}{ Presence IP guideline } & Yes & 100(80.6) & 24(19.4) & $5.16(2.49-10.68)$ & $0.95(0.83-4.55)$ \\
\hline & No & $21(44.7)$ & $26(55.3)$ & 1 & 1 \\
\hline \multirow[t]{2}{*}{ Infection prevention training } & Yes & 114(82.6) & 24(17.4) & $17.64(6.87-45.33)$ & $2.19(1.13-4.75) *$ \\
\hline & No & $7(21.2)$ & $26(78.8)$ & 1 & 1 \\
\hline \multirow[t]{2}{*}{ Availability of continuous water supply } & Yes & $74(52.1)$ & $14(48.3)$ & 1 & 1 \\
\hline & No & $68(47.9)$ & $15(51.7)$ & $0.86(0.34-0.95)$ & $0.48(0.21-0.83)^{*}$ \\
\hline \multirow[t]{7}{*}{ Currently working unit } & Outpatient department & $39(36.1)$ & $12(22.6)$ & 1 & 1 \\
\hline & Emergency and Triage & $9(8.3)$ & $13(24.5)$ & $0.21(0.13-1.24)$ & $0.25(0.13-1.54)$ \\
\hline & Maternity unit & $18(16.7)$ & $5(9.4)$ & $1.11(0.79-1.21)$ & $1.67(0.89-3.61)$ \\
\hline & Inpatient clinic & $7(6.5)$ & $6(11.3)$ & $0.28(0.15-1.63)$ & $0.68(0.34-1.97)$ \\
\hline & Laboratory & $22(20.4)$ & $7(13.2)$ & $0.97(0.53-2.76)$ & $3.24(1.68-6.27){ }^{*}$ \\
\hline & Pharmacy & $7(6.5)$ & $8(15.1)$ & $0.84(0.39-3.03)$ & $0.54(0.17-1.57)$ \\
\hline & Under-five clinic & $6(5.6)$ & $2(3.8)$ & $0.47(0.21-1.35)$ & $0.79(0.36-2.17)$ \\
\hline
\end{tabular}


procedures in the laboratory unit which might improve their knowledge. Besides, this could be due to the difference in infection prevention training among units.

Health workers who had ever attended any form of training program on infection prevention were more likely to practice than those who didn't take training on infection prevention. This is supported by a study done in Ethiopia [18]. According to different international guidelines, infection prevention education \& training is the core components of infection prevention and control programs [33, 34]. Infection prevention and control guidelines in combination with health care workers' education and training are effective to reduce hospital acquired infection [34]. Previous studies have verified that training of health care workers on infection control has a valuable effect on healthcare staff by improving their compliance with the standard precaution $[35,36]$. But the current study showed that only $33.9 \%$ of the health workers had ever attended any form of training program on infection prevention. This implies more than twothird of healthcare providers need training for infection prevention. Similarly, healthcare providers who had infection prevention guidelines were more likely to have safe infection prevention practice than those who had no infection prevention guidelines. The finding highlights the necessity of infection prevention guideline in the improvement of healthcare providers' practice.

Healthcare providers working in health facilities without continuous running water supply were $52 \%$ less likely to have safe infection prevention practices as compared with HCPs working in a facility with continuous water supply. This finding is supported by a study done in Ethiopia [30].

One of the limitation of this study was temporal relationships cannot be established between the explanatory and outcome variables due to the cross-sectional nature of study design. Recall bias might be the other limitation of this study. Finally, since the study was conducted in governmental healthcare facilities, generalizability of the study findings is limited to these governmental healthcare facilities.

\section{Conclusion}

The findings of this study showed that a significant proportion of HCPs had no adequate knowledge on infection prevention and $45 \%$ of healthcare providers practiced infection prevention unsafely. Knowledge towards infection prevention has been significantly associated with work experience, getting of infection prevention training and presence of infection prevention guideline. As a result, to improve knowledge on infection prevention, adequate pre-service as well as on job training for HCPs should be given. Besides, infection prevention guideline should be availed to improve knowledge and practice of infection prevention.

\section{Abbreviations}

AOR: Adjusted Odds Ratio; COR: Crude Odds Ratio; HCP: Health Care provider; IP: Infection Prevention; IPC: Infection Prevention Control; WHO: World Health Organization

\section{Acknowledgments}

None.

\section{Authors' contributions}

$J A$ : conceived of the presented idea and analyzed the data. GD; drafted the manuscript and analyzed the data. SA: gave final approval. All authors approved the final manuscript

\section{Funding}

Not applicable.

Availability of data and materials

The data can be available from corresponding author.

Ethics approval and consent to participate

Ethical clearance was obtained from Woldia University College of Health Science research and community service office (reference number: WU/RCSO 125/11). Informed consent was obtained from each respondents who participated in the study. Confidentiality was maintained by omitting their personal identifications.

Consent for publication

Not applicable.

\section{Competing interests}

The authors declare that they have no competing interests.

\section{Author details}

${ }^{1}$ South Wollo Zonal Department, Dessie, Ethiopia. ${ }^{2}$ Department of Public Health, College of Health Science, Woldia University, Woldia, Ethiopia.

Received: 22 February 2020 Accepted: 12 August 2020

Published online: 17 August 2020

\section{References}

1. WHO. WHO Guidelines on Hand Hygiene in Health Care: a Summary [Internet]. Geneva: WHO; 2009. http://www.who.int/gpsc/5may/tools/en/ index.html.

2. Taffurelli C, Sollami A, Camera C, Federa F, Grandi A, Marino M, et al. Healthcare associated infection: good practices, knowledge and the locus of control in heatlhcare professionals. Acta bio-medica : Atenei Parmensis. 2017:88(3s):31-6.

3. Lacerda RA. Hospital infection and sue relationship with the evolution of health assistance practices. Sao Paulo: Atheneu; 2003.

4. Organization WH. Report on the burden of endemic health care-associated infection worldwide. 2011.

5. Jroundi I, Khoudri I, Azzouzi A, Zeggwagh AA, Benbrahim NF, Hassouni F, et al. Prevalence of hospital-acquired infection in a Moroccan university hospital. Am J Infect Control. 2007;35(6):412-6.

6. Ogwang M, Paramatti D, Molteni T, Ochola E, Okello TR, Ortiz Salgado JC, et al. Prevalence of hospital-associated infections can be decreased effectively in developing countries. J Hosp Infect. 2013;84(2):138-42.

7. Kallel H, Bahoul M, Ksibi H, Dammak H, Chelly H, Hamida CB, et al. Prevalence of hospital-acquired infection in a Tunisian hospital. J Hosp Infect. 2005;59(4):343-7.

8. Yallew WW, Kumie A, Yehuala FM. Risk factors for hospital-acquired infections in teaching hospitals of Amhara regional state, Ethiopia: a matched-case control study. PLoS One. 2017;12(7):e0181145.

9. Alonso-Aguilar NM, Juarez-Enriquez SR, Castro-Escarpulli G, Rivera G, Bocanegra-Garcia V, Guo X, et al. Aetiology and significance of hospitalacquired infections in Mexico. Clin Lab. 2017;63(2):207-18.

10. Guzman-Herrador B, Molina CD, Allam MF, Navajas RF. Independent risk factors associated with hospital-acquired pneumonia in an adult ICU: 4-year prospective cohort study in a university reference hospital. J Public Health (Oxford, England). 2016;38(2):378-83. 
11. Beggs C, Knibbs LD, Johnson GR, Morawska L. Environmental contamination and hospital-acquired infection: factors that are easily overlooked. Indoor Air. 2015;25(5):462-74.

12. Rothe C, Schlaich C, ST. Healthcare-associated infections in sub-Saharan Africa. J Hosp Infect. 2013;85:3-14.

13. Koutzavekiaris I, Vouloumanou EK, Gourni M, Rafailidis PI, Michalopoulos A Falagas ME. Knowledge and practices regarding prevention of infections associated with central venous catheters: a survey of intensive care unit medical and nursing staff. Am J Infect Control. 2011;39(7):542-7.

14. Brisibe S, Ordinioha B, Gbeneolol PK. Knowledge, attitude, and infection control practices of two tertiary hospitals in port-Harcourt, Nigeria. Niger J Clin Pract. 2014;17(6):691-5.

15. Adegboye MB, Zakari S, Ahmed BA, Olufemi GH. Knowledge, awareness and practice of infection control by health care workers in the intensive care units of a tertiary hospital in Nigeria. Afr Health Sci. 2018;18(1):72-8.

16. Deress T, Hassen F, Adane K, Tsegaye A. Assessment of knowledge, attitude, and practice about biomedical waste management and associated factors among the healthcare professionals at Debre Markos town healthcare facilities, Northwest Ethiopia. J Environ Public Health. 2018;2018:7672981.

17. Desta M, Ayenew T, Sitotaw N, Tegegne N, Dires M, Getie M. Knowledge, practice and associated factors of infection prevention among healthcare workers in Debre Markos referral hospital, Northwest Ethiopia. BMC Health Serv Res. 2018;18(1):465.

18. Geberemariyam BS, Donka GM, Wordofa B. Assessment of knowledge and practices of healthcare workers towards infection prevention and associated factors in healthcare facilities of West Arsi District, Southeast Ethiopia: a facility-based cross-sectional study. Arch Public Health. 2018;76:69.

19. Abd Elaziz KM, Bakr IM. Assessment of knowledge, attitude and practice of hand washing among health care workers in Ain Shams University hospitals in Cairo. J Prev Med Hgiene. 2009;50(1):19-25.

20. Engelbrecht M, Janse van Rensburg A, Kigozi G, van Rensburg HD. Factors associated with good TB infection control practices among primary healthcare workers in the Free State Province, South Africa. BMC Infect Dis. 2016;16(1):633

21. Bekele T, Gebremariam A, Kaso M, Ahmed K. Factors associated with occupational needle stick and sharps injuries among hospital healthcare Workers in Bale Zone, Southeast Ethiopia. PLoS One. 2015;10(10):e0140382.

22. Temesgen C, Demissie M. Knowledge and practice of tuberculosis infection control among health professionals in Northwest Ethiopia; 2011. BMC Health Serv Res. 2014;14:593.

23. Woldegioris T, Bantie G, Getachew H. Nurses' knowledge and practice regarding prevention of surgical site infection in Bahir Dar, Northwest Ethiopia. Surg Infect. 2019;20(1):71-7.

24. Alemayehu R, Ahmed K, OS. Assessment of knowledge and practice on infection prevention among health Care Workers at Dessie Referral Hospital, Amhara region, south Wollo zone, north East Ethiopia. J Commun Med Health Educ. 2016;6:4-8.

25. Gulilat K, GT. Assessent of knowledge, attitude and practice of health care workers on infection prevention in health institution Bahir Dar city administration. Sci J Public Health. 2014;2(5):384-93.

26. Biniyam S, Azeb G, Desta H, GT. Infection prevention practices and associated factors among healthcare workers in governmental healthcare facilities in Addis Ababa, Ethiopia. Ethiop J Health Sci. 2018;28(2):177-86.

27. Yakob E, Lamaro $\mathrm{T}, \mathrm{AH}$. Knowledge, attitude and practice towards infection control measures among Mizan-Aman general hospital workers, south West Ethiopia. Commun Med Health Educ. 2015;5:5-9.

28. Gupta A, Kapil A, Lodha R, Sreenivas V. Knowledge, attitude and practice towards infection control among healthcare professionals. Natl Med J India. 2013;26(1):59-60

29. Bedoya G, Dolinger A, Rogo K, Mwaura N, Wafula F, Coarasa J, et al. Observations of infection prevention and control practices in primary health care, Kenya. Bull World Health Organ. 2017;95(7):503-16.

30. Sahiledengle $B$, et al. Infection prevention practices and associated factors among healthcare Workers in Governmental Healthcare Facilities in Addis Ababa. Ethiop J Health Sci. 2018;28(2):2-8.

31. Weldu MG, Berhane H, Berhe N, Haile K, Sibhatu Y, Gidey T, et al. Magnitude and determinant factors of surgical site infection in Suhul hospital Tigrai, northern Ethiopia: a cross-sectional study. Surg Infect. 2018;19(7):684-90.

32. Samuel R, Almedom AM, Hagos G, Albin S, Mutungi A. Promotion of handwashing as a measure of quality of care and prevention of hospitalacquired infections in Eritrea: the Keren study. Afr Health Sci. 2005;5(1):4-13.
33. World Health Organization. Guidelines on core components of infection prevention and control programs at the national and acute health care facility level. Geneva: WHO; 2016.

34. World Health Organization. [Guidelines on Core Components of Infection Prevention and Control Programmes at the National and Acute Health Care Facility Level]. World Health Organization. Country Office for Thailand; 2020.

35. Anwar M, Majeed A, Saleem RM, Manzoor F, Sharif S. Assessment of infection control practices in teaching hospitals of Quetta. J Pakistan Med Assoc. 2016;66(8):947-51.

36. Arinze-Onyia SU, Ndu AC, Aguwa EN, Modebe I, Nwamoh UN. Knowledge and practice of standard precautions by health-Care Workers in a Tertiary Health Institution in Enugu, Nigeria. Niger J Clin Pract. 2018;21(2):149-55.

\section{Publisher's Note}

Springer Nature remains neutral with regard to jurisdictional claims in published maps and institutional affiliations.
Ready to submit your research? Choose BMC and benefit from:

- fast, convenient online submission

- thorough peer review by experienced researchers in your field

- rapid publication on acceptance

- support for research data, including large and complex data types

- gold Open Access which fosters wider collaboration and increased citations

- maximum visibility for your research: over $100 \mathrm{M}$ website views per year

At BMC, research is always in progress.

Learn more biomedcentral.com/submissions 